\title{
Characterization of the pilF-pillD pilus-assembly locus of Neisseria gonorrhoeae
}

\author{
Nancy E. Freitag, ${ }^{1}$ H. Steven Seifert ${ }^{2}$ and \\ Michael Koomey ${ }^{1}$ * \\ 'Department of Microbiology and Immunology, \\ University of Michigan Medical School, Ann Arbor, \\ Michigan 48109-0620, USA. \\ ${ }^{2}$ Department of Microbiology-Immunology, Northwestern \\ Medical School, Chicago, Illinois 60611, USA.
}

\section{Summary}

Expression of Type IV pili by the bacterial pathogen Neisseria gonorrhoeae appears to be essential for colonization of the human host. Several N. gonorrhoeae gene products have been recently identified which bear homology to proteins involved in pilus assembly and protein export in other bacterial sys. tems. We report here the isolation and characterization of transposon insertion mutants in $N$. gonorrhoeae whose phenotypes indicate that the $N$. gonorrhoeae pilf and pilD gene products are required for gonoccocal pilus biogenesis. Mutants lacking the pilD gene product, a pre-pilin peptidase, were unable to process the pre-pilin subunit into pilin and thus were nonpiliated. pilf mutants processed pilin but did not assemble the mature subunit. Both classes of mutants released S-pilin, a soluble, truncated form of the pilin subunit previously correlated with defects in pilus assembly. In addition, mutants containing transposon insertions in pilD or in a downstream gene, orfX, exhibited a severely restricted growth phenotype. Deletion analysis of piID indicated that the poor growth pheno. type observed for the pilD transposon mutants was a result of polar effects of the insertions on orf $X$ expres. sion. orfX encodes a predicted polypeptide of $23 \mathrm{kDa}$ which contains a consensus nucleotide-binding domain and has apparent homologues in Pseudomonas aeruginosa, Pseudomonas putida, Thermus thermophilus, and the eukaryote Caenorhabditis elegans. Although expression of orfX and pilD appears to be transcriptionally coupled, mutants containing transposon insertions in or $f X$ expressed pili. Unlike either pilF or pilD mutants, orfX mutants were also competent for DNA transformation.

Received 22 November, 1994; revised 17 January, 1995; accepted 23 January, 1995. *For correspondence. Tel (312) 763 3672; Fax (312) 7643562 .

\section{Introduction}

The expression of pili by Neisseria gonorrhoeae plays an essential role in gonoccocal colonization of the human host. Pili are filamentous appendages which consist of a polymerized protein subunit of $18-24 \mathrm{kDa}$ known as pilin; this polypeptide is to date the only recognized integral component of the pilus organelle. The short leader sequence and proximal 30 amino acids of gonococcal pre-pilin have a high degree of homology with Type IV pre-pilins of other Gram-negative organisms including Neisseria meningitidis (Potts and Saunders, 1988), Moraxella species (Tonjum et al., 1991; Marrs et al., 1985), Dichelobacter nodosus (Elleman and Hoyne, 1984), Pseudomonas aeruginosa (Strom and Lory, 1986), Vibrio cholerae (Shaw and Taylor, 1990), and the pilin of certain strains of enteropathogenic Escherichia coli (Giron et al., 1991).

A strong correlation exists between pilus expression and the ability of $N$. gonorrhoeae to colonize humans, its sole host. Non-piliated mutants fail to colonize the urethras of male volunteers (Kellog et al., 1968; Swanson ef al., 1987 ) and results from several studies support the notion that pili facilitate adherence of the bacterium to the mucosal surface (Swanson, 1973; McGee et al., 1981; Heckels, 1989). Pilus expression therefore appears to be a requisite determinant of infectivity and the organelle may be thought of as a colonization factor.

Previous attempts to isolate and characterize pilus assembly mutants in gonococci have met with limited success. Mutations within the pilin subunit occur frequently as a consequence of the recombination process responsible for antigenic variation (Koomey et al., 1987), and even in recombination-deficient strains, pilin mutations account for a majority of non-piliated mutants. Despite these difficulties, PilC, a $110 \mathrm{kDa}$ protein which co-purifies with the gonococcal pilin subunit has been identified, and gonococcal mutants which fail to express PilC were reported to express few, if any, pili (Jonsson et al., 1991). Recent reports indicate, however, that it is possible to isolate gonococcal suppressor mutants which regain pilus expression in the absence of PilC; thus the precise role of PilC in pilus assembly remains unclear (Rudel et al., 1992).

An examination of proteins involved in Type IV pilus biogenesis in other systems has revealed that they are structurally and functionally related to components required for 
the two-step (signal-sequence dependent) translocation of proteins to the exterior of the cell in many prokaryotic systems. Type IV pilus biogenesis proteins share identity with proteins involved in protein secretion, morphogenesis of filamentous bacteriophages, and DNA transfer by conjugation and transformation (Hobbs and Mattick, 1993; Pugsley, 1993; Strom and Lory, 1993). Based on these homologies, several genes were recently identified in $N$. gonorthoeae whose products appear related to proteins required for Type IV pilus assembly and for transport of large molecules across the bacterial cell surface (Lauer et al., 1993). Two of these genes, pilD and pilf, were found to map to a single locus remote from the pilin expression locus, pilE, where the pilus subunit-encoding gene is found (Lauer et al., 1993). Both pilD and pilf share significant structural relatedness to proteins found in virtually all of the two-step protein export pathways that have been genetically dissected. The pilD gene product has a high degree of similarity with the $P$. aeruginosa cytoplasmic membrane-localized pre-pilin peptidase encoded by pilD/ xcpA (Nunn et al., 1990; Bally et al., 1991) as well as the pulO gene of Klebsiella oxytoca (Pugsley and Reyss, 1990), the comC gene of Bacillus subtilis (Mohan et al., 1989), and the tcpJ gene of V. cholerae (Kaufman et al., 1991). When expressed in E. coli, the N. gonorrhoeae pilD gene product was shown to process gonoccocal pre-pilin (Lauer et al., 1993; Dupuy and Pugsley, 1994) as well as the pilin-like proteins PulG of $K$. oxytoca (Dupuy and Pugsley, 1994) and ComGC of B. subtilis (Chung and Dubnau, 1995), indicating that PID is indeed a pre-pilin leader peptidase. pilF, which shares homology with P. aeruginosa pilB (Nunn et al., 1990), K. oxytoca pulE (Pugsley et al., 1990), Xanthomonas campestris xpsE (Dums et al., 1991), V. cholerae epsE (Sandkvist et al., 1993), and comG1 of B. subtilis (Albano et al., 1989), encodes a gene product which has an overall hydrophilic character with a lack of obvious membrane-spanning regions, and possesses a consensus nucleotide-binding site (Walker et al., 1982). The structural integrity of the nucleotide-binding domain has been shown to be essential for PilB-dependent pilus assembly and XcpRdependent protein secretion in $P$. aeruginosa (Turner et al., 1993) and PulE-dependent secretion of pullulanase in K. oxytoca (Possot and Pugsley, 1994). In summary, N. gonorrhoeae PilD and PilF share significant homology with proteins involved in Type IV pilus assembly and protein-export pathways; however, it remained to be demonstrated whether these two gene products participated in gonococcal pilus expression.

In this work, we show that both the pilD and the pilf gene products are essential for pilus assembly in $\mathrm{N}$. gonorrhoeae since strains containing mutations in either gene were absolutely defective in pilus expression. The mutants were also found to release S-pilin, a truncated form of the pilin subunit protein which has been associated with reduced levels of piliation or absence of pilus assembly (Koomey et al., 1991; Haas et al., 1987; Koomey et al., 1987; Swanson et al., 1986). In addition, the pilD and pilF gene products were found to be required for competence, a property tightly associated with pilus expression in N. gonorrhoeae (Sparling, 1966; Biswas et al., 1977; Biswas et al., 1989) although the relationships between the two processes are unclear. Lastly, we have identified an additional gene, or $X$, located downstream of pilD. Although orf $X$ and pilD are co-transcribed, mutants containing transposon insertions in orf $X$ assembled pili and were competent for DNA transformation but exhibited a severely restricted growth phenotype.

\section{Results}

Transposon mutagenesis of the N. gonorrhoeae pilFpilD region

To determine if the pilF and pilD gene products are

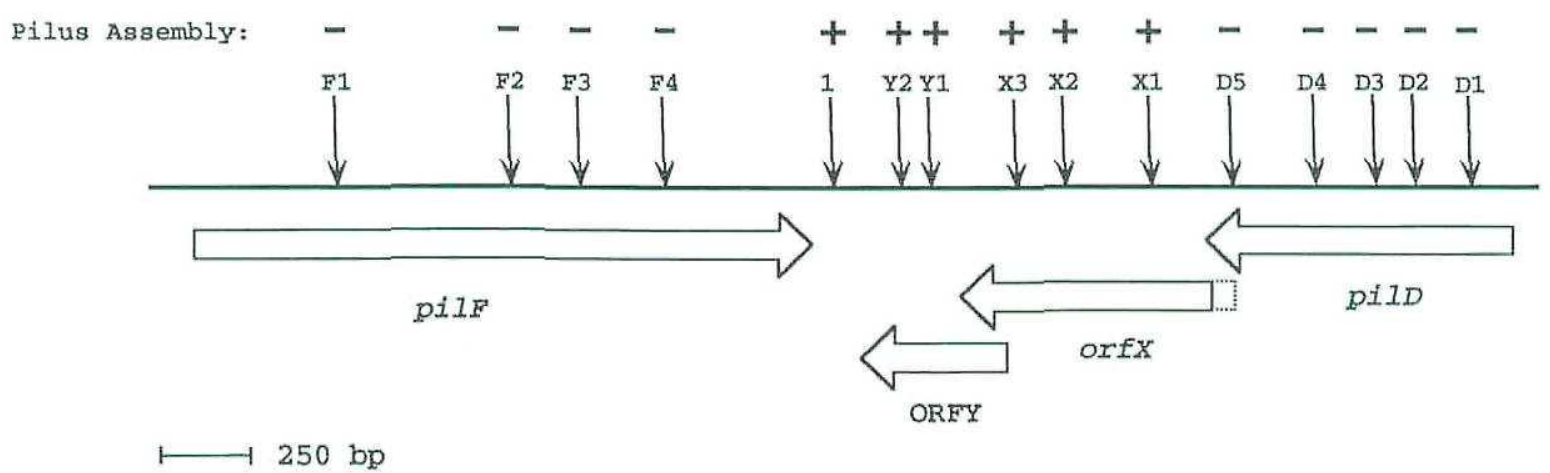

Fig. 1. Map of the pilF-pilD locus and location of transposon insertion mutations. Large open arrows indicate gene location and orientation. Vertical arrows designate sites of $\mathrm{m}$-Tn3erm transposon insertions. Gonococcal strains containing transposon insertion mutations are designated with a $G$ followed by the location of the $m$-Tn3erm as depicted above (for example, GFy represents the gonococcal mutant carrying the F1 pilf::m-Tn3erm). 

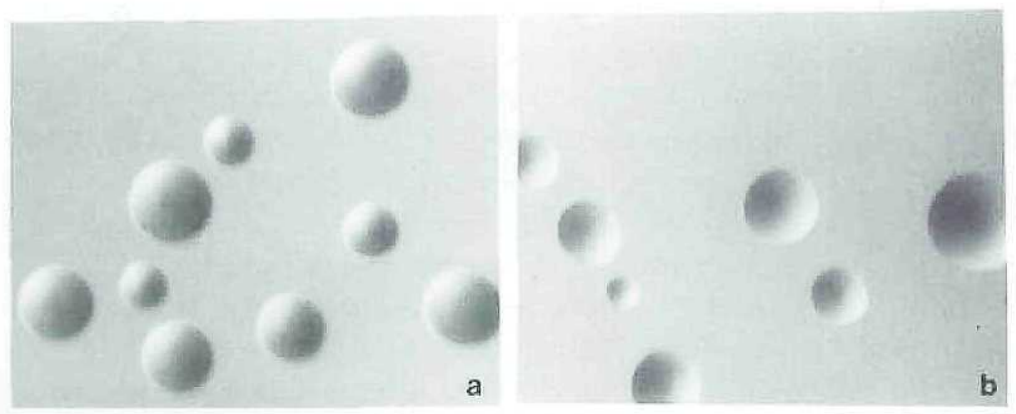

Fig. 2. Colony morphologies of gonococcal transposon insertion mutants. (a) N400 (wild type); (b) GF2 (pilf::m-Tn3erm); (c) GD3 (pilD::m-Tn3erm); (d) GD (Clal $\rightarrow$ Xhol), (pilD frameshift mutant); (e) GY1 (ORFY::mTn3erm): (f) GX2 (orfX::m-Tn3erm).

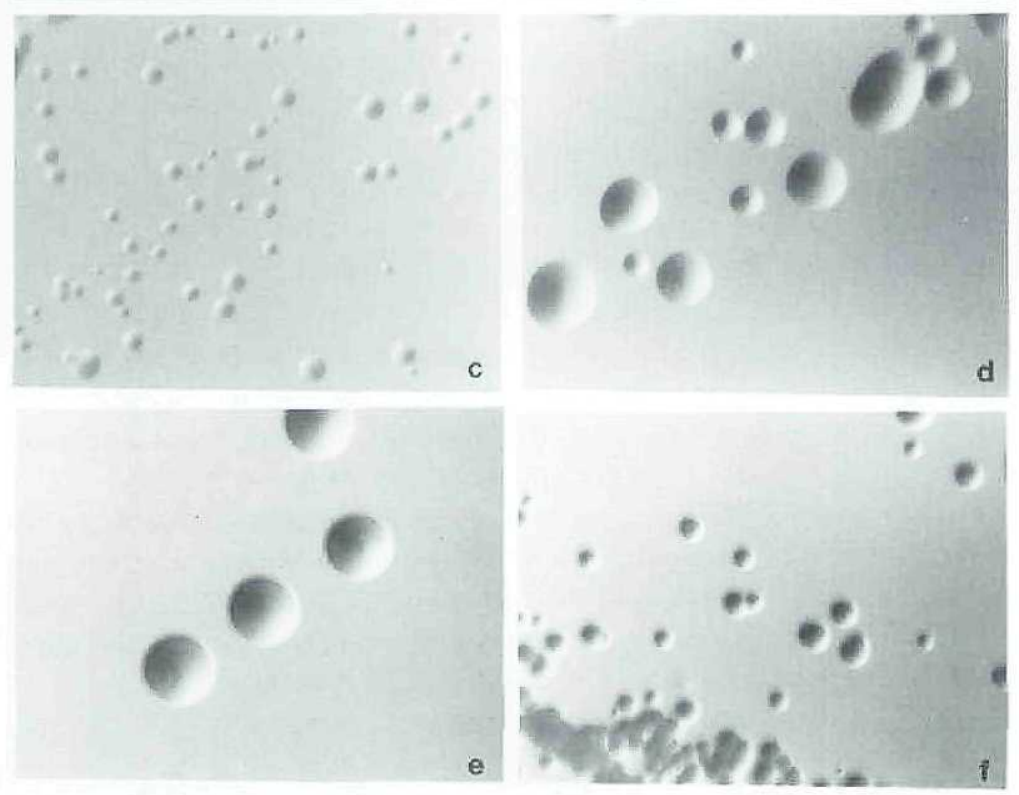

required for $N$. gonorrhoeae pilus assembly, a plasmid containing pilF-pilD sequences was subjected to saturated transposon mutagenesis as described in the Experimental procedures. Selected insertions (shown in Fig. 1) were then moved by transformations onto the chromosome of strain $\mathrm{N} 400$ which carries the recA gene under the control of an IPTG-inducible promoter. In the absence of induction, $\mathrm{N} 400$ bacteria are essentially RecA- , thereby preventing pilE gene rearrangements (Koomey et al., 1987). Transformations were carried out in the presence of IPTG to enable homologous recombination of the mutations into the chromosome. Distinct differences in colony morphologies of transposon insertion mutants were readily apparent in the transformants (Fig. 2). All pilF and pilD mutants lost the aggregative phenotype (a well-defined colony edge) observed for the piliated $\left(\mathrm{P}^{+}\right)$parent $\mathrm{N} 400$ strain and similarly failed to autoagglutinate when grown in liquid culture. N. gonorrhoeae mutants containing transposon insertions within pilD and in a 600 bp region located immediately downstream of pilD formed petite, slowgrowing colonies, although transposon mutants carrying insertions downstream of pilD retained a piliated colony

Table 1. Phenotypes of pilF-pilD region transposon insertion mutants.

\begin{tabular}{llclcc}
\hline Strain & Description & Pili $^{\text {a }}$ & $\begin{array}{l}\% \text { Competence for } \\
\text { DNA transiormation }\end{array}$ & $\begin{array}{c}\text { Growth } \\
{ }^{c}\end{array}$ & $\begin{array}{c}\text { Pre-pilin } \\
\text { processing }\end{array}$ \\
\hline N400 & Wild type & + & $100 \%$ & +++ & + \\
GF2 & pilF::m-Tn3erm & - & $<0.1 \%$ & +++ & + \\
GD3 & pilD::m-Tn3erm & - & $<0.1 \%$ & + & + \\
GX2 & orf $:: m-T n 3 e r m$ & + & $100 \%$ & + & + \\
GY1 & ORFY::m-Tn3erm & + & $100 \%$ & +++ & + \\
G-1 & Intergenic m-Tn3erm & + & $100 \%$ & +++ & + \\
\hline
\end{tabular}

a. As assayed by transmission electron microscopy.

b. Measured under recA-induced conditions.

c. in rich peptone-based media. 
morphology (Fig. 2). In contrast, transposon insertion mutants G-1 and GY1 were indistinguishable in their patterns of growth from the parent strain.

N. gonorrhoeae pilF and pilD are required for pilus assembly and competence.

The transposon insertion mutants were examined for the expression of assembled pili. Southern analysis of the pilF and pilD mutants indicated that these genes are present in single copy in the gonococcal chromosome (data not shown). Transposon insertions within pilF or pilD eliminated pilus assembly as detected by transmission electron microscopy (Table 1, data not shown). The remaining transposon mutants expressed pili on their cell surfaces, therefore gene products encoded by potential genes located between pilF and pilD are not required for pilus assembly. The nucleotide sequences of pilE (the pilin subunit gene) were determined for the non-piliated mutants and found to be unaltered. The results indicated that defective pilus expression in these mutants could not be ascribed to changes in pilin gene status. The phenotypes of pilF and pilD mutants thus demonstrate that both gene products are required for pilus assembly.

Competence for DNA transformation is a pilusassociated phenotype (Sparling, 1966; Biswas et al.. 1977; Biswas et al., 1989). The transposon insertion mutants were examined for relative competence by selection for a drug-resistance marker following DNA transformation using genomic DNA from either rifampicin- (Rif ${ }^{R}$ ) or nalidixic acid-resistant $\left(\mathrm{Nal}^{\mathrm{R}}\right)$ gonococcal strains. The pilF and pilD transposon insertion mutants had greatly reduced transformation frequencies in comparison to the parent strain, whereas the remaining transposon insertion mutants appeared fully competent (Table 1). The transformation frequencies observed for both pilF and pilD mutants are similar to those observed for non-piliated $N$. gonorrhoeae strains containing mutations located within pilE, the gene encoding the pilin subunit (Seifert et al., 1990; Zhang et al., 1992) and pilG, encoding an essential pilus assembly factor (Tonjum et al., 1995).

\section{Identification of iwo open reading frames located between pilF and pilD}

Analysis of sequence data from the intergenic region between pilF and pilD indicated the presence of two large open reading frames (ORFs), designated here as ORFX and ORFY (Fig. 1). Based on sequence analysis, the ATG initiation codon of ORFX may overlap the stop codon of pilD; alternatively, the protein may begin from an ATG located within pilD coding sequences. Neither start codon appears to have a consensus ribosome-binding site preceding it (Gold, 1988). ORFX was predicted to

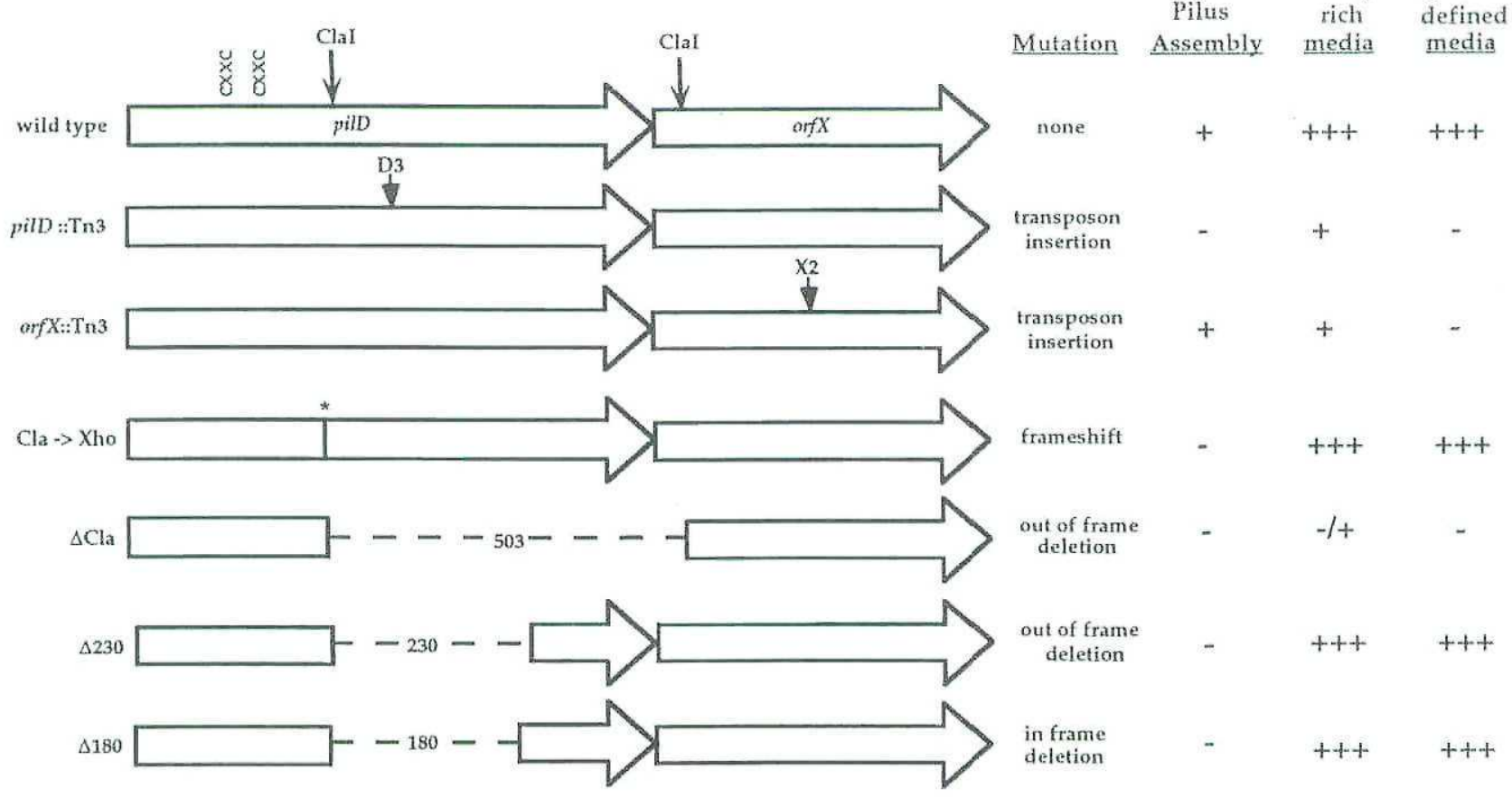

Fig. 3. Genotypes and phenotypes of pilD and orf $X$ mutants. Unmarked mutations were introduced into N400 by selection for a downstream transposon-encoded antibiotic-resistance marker as described in the Experimental procedures. 
for the pilD transposon insertion mutants therefore appears to be the result of polar effects of the transposon on ORFX expression and suggests that piID and ORFX are transcriptionally linked. We infer from this genetic evidence that OrfX is indeed a functional product expressed in $N$. gonorrhoeae, and have designated the gene orf $X$.

N. gonorrhoeae OrfX has potential homologues in $\mathrm{P}$. aeruginosa, Pseudomonas putida, Thermus thermophilus, and Caenorhabditis elegans

A database search revealed no obvious homologies for the ORFY open reading frame. OrfX, however, shared significant identity with three other ORFs, all of which contain a consensus nucleotide-binding sequence or Walker box A (Walker et al., 1982) (Fig. 4). An ORF located downstream from a putative insertion sequence element in T. thermophilus shares 37\% identity and 54\% similarity (Ashby and Berquist, 1990), and an ORF identified in the nematode $C$. elegans shares $32 \%$ identity and $52 \%$ similarity (Wilson et al., 1994). However, neither of the protein products encoded by these putative genes has been assigned any function. An additional ORF homology was found encoded by a potential gene, orf $X$, located immediately downstream of the pilD peptidase gene of $P$. putida (deGroot et al., 1994). The orientation of the $P$. putida or $X X$ with respect to the pilD encoded peptidase is identical to the orientation of pilD and orf $X$ observed in $N$. gonorrinoeae, and includes the overlap of the potential orfX translation intitiation codon with the stop codon of pilD. N. gonorrhoeae OrfX and P. putida OrfX share $40 \%$ identity and $56 \%$ similarity. It is worth noting that a similar partial ORF exists downstream of $P$. aeruginosa pilD (Bally et al., 1991) but the entire sequence of this region has not been reported. OrfX homology, including the nucleotidebinding consensus domain, can be recognized in the translation of the partial sequence immediately downstream of $P$. aeruginosa pilD, and additional homology extends through an alternative reading frame within the reported sequence (Fig. 4).

\section{N. gonorhoeae pilD mutants fail to process pre-pilin}

Expression and processing of the pre-pilin subunit protein was examined in the transposon and pilD deletion mutants (Fig. 5). Polyclonal antibodies generated against purified pili isolated from N. gonorrhoeae were used in Western analysis of whole-cell lysates. Strains containing transposon insertions or deletions in pilD did not process prepilin as evidenced by the presence of a slower migrating form of the pilin subunit in these strains, which comigrates with a pre-pilin resistant to pre-pilin peptidase cleavage (Koomey et al., 1991; Fig. 5, top panel, lanes $7-9)$, It has been previously demonstrated that antibodies generated against $P$. aeruginosa PAK pili recognize only processed pilin in N. gonorrhoeae (Koomey et al., 1991). The failure of these antibodies to recognize the pilin subunit in pilD mutants confirms the lack of processing (Fig. 5, lower panel, lanes 7-9). Mutants with transposon insertions in pilF, orf $X, O R F Y$, and the intergenic region between pilF and ORFY all processed pre-pilin to the faster migrating form (Fig. 5, lanes 3-6). The production of S-pilin was also observed in the pilF and pilD mutants indicating that neither PilF nor PilD function is required for this altered form of processing.

In the parent strain, the processed pilin subunit has been observed to migrate as a doublet and pilin purified from assembled pili migrates as the lower band of the doublet (Koomey et al., 1991). Interestingly, pilf mutants and, to a lesser extent, orf $X$ mutants, display the upper band of the doublet as the predominant subunit species, whereas in the parent strain the lower band predominated. That both species appear to have been processed by pre-pilin leader peptidase suggests that an additional form of post-translational pilin processing exists but its nature and significance remains unknown. Studies in $P$. aeruginosa have indicated that methylation does not alter the

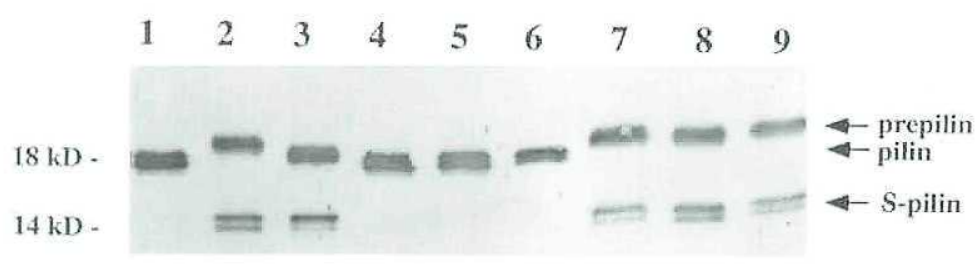

Fig. 5. Immunoblotting of whole cell lysates to detect pilin expression. Polyclonal GC2-66 antibody generated against purified gonococcal pili (upper panel) or polyclonal PAK 2-567 antibody generated against purified pili from $P$. aeruginosa PAK (lower panel) was used to identify pilin antigen. Samples were standardized for total protein. Lanes: (1) N400 (wild type); (2) VD302 $\mathrm{P}^{-}$(Gly-1 $\rightarrow$ Ser-1); (3) GF2 (pilF::m-Tn3erm); (4) G-1 (intergenic m-Tn3erm); (5) GY1 (ORFY::m-Tn3erm); (6) GX2 (orfX::m-Tn3erm); (7) GD3 $($ pill ::m-Tn3erm); (8) GD $($ Clal $\rightarrow$ Xhol): (9) GDA180 (in-frame pilD deletion). 
relative mobility of pilin in that system (Strom et al., 1993); however, we have not yet determined the methylation status of the pilin doublet.

\section{Characterization of a pilD-orfX deletion mutant}

pilD transposon insertion mutants grew at rates slightly slower than orf $X$ mutants. It thus appeared that mutants deficient in both pilD and orfX expression were more severely growth restricted than mutants carrying only the orfX gene lesion. We therefore constructed a deletion mutation, which would disrupt both pillD and orf $X$, to assess the phenotypes associated with loss of both gene products. The construction, created by deletion of a $0.5 \mathrm{~kb} \mathrm{Clal} \mathrm{fragment} \mathrm{(Fig.} \mathrm{3),} \mathrm{was} \mathrm{introduced} \mathrm{into} \mathrm{the}$ chromosome of $\mathrm{N} 400$ by transformation and selection for a downstream transposon-encoded antibiotic-resistance gene. This mutation results in the deletion of sequences encoding the C-terminal 141 amino acids of PilD and $\mathrm{N}$-terminal 42 amino acids of the smaller predicted OrfX polypeptide but does not translationally fuse the two reading frames. Two colony types were observed among the erythromycin-resistant transformants. One class of transformants was visible after 24 hours of growth and resembled the $\mathrm{P}^{++}$parent strain. These mutants were found to have only crossed in the transposon-linked antibiotic-resistance gene and not the upstream deletion. After four days of incubation, tiny colonies were visible on the transformation plates, which were not visible on plates of bacteria transformed with control DNA lacking the deletion but bearing the linked transposon insertion. The severe growth restriction of these mutants was somewhat alleviated when the cells were grown in the absence of antibiotic (data not shown). Attempts to isolate genomic DNA sufficient for Southern analysis from these ultrapetite colonies were unsuccessful. The extreme restricted growth phenotype exhibited by the pilD-orf $X$ double mutant suggests that loss of both gene products has a dramatic effect on cell viability, much greater than that observed with loss of orf $X$ alone. However, after several days of growth, non-piliated faster growing variants could be observed within the mutant populations. Although these variants exhibited improved growth in rich media, they remained unable to grow in defined media. Southern analysis of genomic DNA isolated from these latter variants indicated that they indeed carried the $0.5 \mathrm{~kb}$ Clal deletion. To assess the status of pilin in the pilD-orfX deletion mutants, Western analysis of six independently arising fast-growing variants was performed. The fast-growing pseudorevertants were found to be composed of two distinct classes. In four of the six cases, pilin expression was dramatically decreased (Class I), whereas in the other two cases no pilin antigen was detected (Class II). In the Class I mutants, the pilin subunit migrated at the position of unprocessed pilin (data not shown).

\section{Discussion}

The findings detailed here indicate that the pilD and pilF gene products are required by $N$. gonorrhoeae for pilus assembly. Transposon insertions in either gene or deletions within pilD completely eliminated detectable pili on the bacterial cell surface. In addition, pilf and pilD mutants were found to release S-pilin, a soluble truncated form of pilin which correlates with defects in pilus assembly (Koomey et al., 1991; Haas et al., 1987; Koomey et al., 1987; Swanson et al., 1986). Both classes of mutants expressed the pre-pilin subunit at normal levels, but pilD mutants lacked pre-pilin peptidase activity and were unable to process pre-pilin to mature pilin. The results presented here confirm the identities of these two gene products as Type IV pilus-assembly proteins in N. gonorrhoeae and as functional members of an extensive family of proteins involved in the transport of macromolecules into and out of the bacterial cell. The pilf and pilD gene products, in addition to the recently described PilG protein (Tønjum et al., 1995), therefore represent the first unambiguous identifications of proteins absolutely required for pilus assembly in N. gonorrhoeae.

in addition to pilus assembly, the data presented here indicate that the pilF and pilD gene products are required for competence for DNA transformation. Competence has been shown to be a pilus-associated property as non-piliated variants have been shown to be dramatically reduced in competence for DNA transformation (Sparling, 1966; Biswas et al., 1977; Biswas et al., 1989; Seifert et al., 1990; Zhang et al., 1992). However, the relationship between pilus expression and competence is not well understood and it is not known whether pili are structural components of the machinery for DNA binding and uptake or if expression of a competent phenotype is perhaps coregulated with, or in some other way dependent upon, pilus biogenesis. Efforts to detect DNA-binding activity by purified pilin subunit or by assembled pili have been unsuccessful (Mathis and Scocca, 1984; Sparling et al., 1977). Homologues of PilF and PilD (the ComG-1 and ComC proteins, respectively) are required in B. subtilis for natural competence (Albano et al., 1989; Mohan et al., 1989), and it has been proposed that the two B. subtilis proteins are necessary for formation of a complex which transports DNA into the bacterium (Dubnau, 1991). It is possible then that PilF and PilD may be necessary for formation of a similar complex in $N$. gonorrhoeae but it remains to be determined whether or not separate complexes exist for pilus assembly and DNA processing.

The orf $X$ gene and an additional open reading frame ORFY are located downstream of pilD. orfX and ORFY 
transposon-insertion mutants expressed pili and were transformable, therefore their products were not required for either pilus assembly or competence. Transposon insertion mutations, which would disrupt expression of ORFY, had no discernible phenotypic difference from the parent $N$. gonorrhoeae strain used in these studies, and so far we have no genetic or biochemical data for the existence of an ORFY-derived polypeptide. In contrast, insertions in orf $X$ dramatically affected bacterial growth. orf $X$ mutants formed petite, dark coloured opaque colonies and displayed extremely low efficiencies of plating. Examination of the mutants by both light and electron microscopy revealed a high level of cell lysis (data not shown). In addition, the mutants failed to grow in defined media. This genetic evidence lends support to the existence and expression of the OrfX polypeptide, encoded by $\operatorname{orf} X$, in $N$. gonorrhoeae.

The function of the orfX gene product is not known, although it is clearly important for bacterial viability. The extreme degree of conservation within the OrfX homologue family is particularly striking in this regard (Fig. 4). Pairwise aligments of the homologues reveal that they all share at least $30 \%$ identity with one another (data not shown) and that the homologies span the full lengths of the polypeptides. The cross phylum matches found in this family make the similarities even more remarkable and may indicate that OrfX homologues function in an intrinsically fundamental aspect of metabolism. Surprisingly, the $C$. elegans orfX gene contains introns, and the location of these introns may perhaps be useful in defining modular domains of the OrfX protein (Gilbert et al., 1986). Dupuy and Pugsley (1994) used Southern analysis to demonstrate that Neisseria meningitidis and other Neisseria species all contained a 500-700 bp Clal fragment which hybridized to a pilD-derived DNA probe. The conservation of the Clal site downstream of pilD coding sequences (defined as a 500 bp fragment) suggests that the organization of orf $X$ and pilD may be conserved across Neisseria species.

Although not essential for pilus biogenesis, several observations suggest that the orf $X$ gene product may play a role related to pilus expression or PilD peptidase activity. Expression of orf $X$ is transcriptionally coupled to pilD and the OrfX phenotypes of mutants containing transposon insertions located near the 5 end of pilD (GD1 (Fig. 1), for example) and larger deletions of pilD coding sequences (data not shown) support the notion that orf $X$ transcription initiates upstream of pilD. Western analysis of orfX mutants using antibody directed against purified gonoccocal pili revealed the presence of several polypeptide species, distinct from pilin, with altered mobility compared to the parental strain (data not shown). These polypeptides may represent pilus-associated proteins, and the differences in mobility observed may potentially reflect incorrect localization of the proteins or errors in processing or post-translational modification. Finally, construction of a mutant carrying a deletion spanning both pilD and orf $X$ resulted in ultrapetite colonies which were more severely growth restricted than orf $X$ mutants. These ultrapetite colonies gave rise to faster growing sub-populations which had decreased expression of prepilin. It appears then that the growth restriction of pilDorf $X$ double mutants in rich media can be compensated for by a reduction in pre-pilin expression. However we have not yet ruled out the possibility that other compensating mutations may have occurred. It is not known at this time if the poor growth phenotype of the pilD-orfX double mutants results from the orf $X$ mutation in the context of a lack of PilD, pre-pilin processing or pilus assembly in general. If the latter case is true, one would expect a similar phenotype to be observed for orí $X$-pilf double mutants. Although no distinguishable phenotype has yet been observed for ORFY mutants, it is possible that loss of ORFY expression may be contributing to the decreased viability of the pilD-orfX Clal deletion mutants. However, as mentioned above, we have no genetic or biochemical evidence to support the existence and expression of the ORFY polypeptide.

The poor growth of pilD-orfX double mutants may explain previous difficulties in generating gonococcal pilD mutants (Dupuy and Pugsley, 1994), as the constructs used in those experiments to create pilD lesions would in retrospect have eliminated both pilD and orf $X$ expression. The pilD-orf $X$ deletion mutants generated here were more sensitive to erythromycin than the other transposon mutants; it is possible that the double mutants would be hypersensitive to chloramphenicol, the selective marker employed by Dupuy and Pugsley (1994).

The possible relationship between pre-pilin processing/ pilus assembly and OrfX, revealed by the dramatic loss in viability of the pilD-orf $X$ double mutants, may provide an insight into OrfX function. Indeed, N. gonorrhoeae may provide a model system for assigning a role for OrfX and its homologues in other systems based on the phenotypes of $N$. gonorrhoeae or $\mathrm{X}$ mutants. No effect on growth has been reported for transposon insertions isolated in the pilD peptidase gene of $P$. aeruginosa (Nunn et al., 1990) although, as previously described, potential orf $X$ coding sequences exist downstream of pilD. It is possible that the orf $X$ gene product is not expressed in $P$. aeruginosa, or that its expression is not linked to that of pilD as it is in N. gonorrhoeae. To our knowledge, mutants bearing lesions within the potential orfX of $P$. aeruginosa have not yet been directly examined; similarly, no relevant mutants have yet been constructed in $C$. elegans or $T$. thermophilus orf $X$. Pilus assembly has not been observed in $P$. putida despite the presence of Type IV pilus assembly homologues (deGroot et al., 1994), thus a possible link 
between pilus assembly and OrfX function may be difficult to assess in this organism.

Preliminary data using antibodies directed against PilD and OrfX suggest the proteins are expressed at very low levels in N. gonorrhoeae (data not shown). Koga et al. (1993) have reported that low levels of $P$. aeruginosa PilD protein are sufficient to process pre-pilin and precursors of components of the extracellular secretion machinery and that PilD appears to be expressed in $P$. aeruginosa at levels 10 -fold higher than needed. A similar situation may exist for PiID (and perhaps OrfX) in N. gonorrhoeae. Experiments are currently underway to gain an understanding of OrfX function. We are using reconstitution experiments to determine the basis for the growth defect observed for orf $X$ mutants in defined media, and are determining the importance of the consensus nucleotide binding site for OrfX activity. The results obtained from these experiments, and from experiments designed to address the specific functional roles of PilF and PiID, will enable a more detailed understanding of the mechanism of pilus assembly in N. gonorrhoeae.

\section{Experimental procedures}

\section{Bacterial strains, plasmids, and transposon mutagenesis}

The bacterial strains used in this study are described in Table 2.

Plasmid pVD300-recA6 contains the N. gonorrhoeae recA gene under the control of an inducible lac promoter as well as repressor $\mathrm{lacl}^{q}$ and a tetracyline resistance gene (tetM), and will be described in detail elsewhere. This plasmid was transformed into N. gonorrhoeae VD300 (Koomey et al., 1987) to produce strain $\mathrm{N} 400$, which was used as the parent strain for all mutant constructions. N400, with its IPTG-inducible copy of recA, allows stable expression of the pilE locus in the absence of induction, and in the presence of IPTG permits transformation of selectable markers into the chromosome. $\mathrm{N} 400$ was propagated on clear solid medium at $36^{\circ} \mathrm{C}$ in $5 \%$ $\mathrm{CO}_{2}$ or in this media lacking agar that had been preincubated overnight in $5 \% \mathrm{CO}_{2}$ (Koomey et al., 1987). Chemically defined media containing free amino acids were prepared as previously described (Catlin, 1973). E. coli strain HB101 was used in plasmid cloning experiments and was grown at $37^{\circ} \mathrm{C}$ in Luria-Bertani (LB) medium supplemented with the appropriate antibiotics.

Transposon mutagenesis of the pilF-pilD region was carried out as described by Seifert et al. (1990). A $3.2 \mathrm{~kb}$ BamHI-Smal fragment was isolated from plasmid p12/7/1 (Lauer et al., 1993) and cloned into mutagenesis vector pHSS6 to create plasmid pF. Transposon insertions were isolated in E. coli host strains as described (Seifert et al., 1990) and sequenced using primer Tn3L (5'-CTCATGACCAAAATCCC- $3^{\prime}$ ) (Seifert and Wilson, 1992) to determine the location of transposon insertion. Plasmid DNA containing insertions of interest (see Fig. 1) was transformed into N400 and transformants were obtained by selection on agar plates containing
Table 2. Bacterial strains.

\begin{tabular}{|c|c|c|}
\hline Strain & Relevant characteristics & $\begin{array}{l}\text { Sourcel } \\
\text { Peference }\end{array}$ \\
\hline N400 & $\begin{array}{l}\text { Derived from } V D 300^{a} \text {. } \\
\text { Contains the recA6 allele } \\
\text { (IPTG-inducible) }\end{array}$ & This work \\
\hline $\begin{array}{l}\text { VD302 } P^{-} \\
\text {Gly-1 } \rightarrow \text { Ser-1 }\end{array}$ & $\begin{array}{l}\text { Mutant pilin resistant to } \\
\text { pre-pilin peptidase activity }\end{array}$ & $\begin{array}{l}\text { Koomey el al. } \\
\text { (1991) }\end{array}$ \\
\hline $\mathrm{GF}^{\mathrm{b}}$ & pilF::m-Tn3erm at position $1232^{\mathrm{c}}$ & This work \\
\hline GF2 & pilF::m-Tn3erm at position $1424^{\mathrm{C}}$ & This work \\
\hline GF3 & pilF::m-Tn3erm at position $1620^{\circ}$ & This work \\
\hline G-1 & m-Tn3erm at position $1059^{d}$ & This work \\
\hline GY1 & ORFY::m-Tn3erm at position $836^{d}$ & This work \\
\hline GY2 & ORFY:m-Tn3erm at position $861^{\mathrm{d}}$ & This work \\
\hline $\mathrm{G} \times 1$ & orf $X:: m-T n 3 e r m$ at position $281^{d}$ & This work \\
\hline $\mathrm{G} \times 2$ & orf $X:: m-T n 3 e r m$ at position $464^{d}$ & This work \\
\hline $\mathrm{G} \times 3$ & orf $X:: \mathrm{m}-\mathrm{Tn} 3 \mathrm{erm}$ at position $670^{\mathrm{d}}$ & This work \\
\hline GD1 & pilD::m-Tn3erm at position $317^{\circ}$ & This work \\
\hline GD2 & pilD : $\mathrm{m}-\mathrm{Tn} 3 \mathrm{erm}$ at position $421^{\circ}$ & This work \\
\hline GD3 & pilD::m-Tn3erm at position $525^{\circ}$ & This work \\
\hline GD4 & pilD ::m-Tn3erm at position $655^{\mathrm{c}}$ & This work \\
\hline GD5 & pilD::m-Tn3erm at position $904^{C}$ & This work \\
\hline $\mathrm{GD}(\mathrm{Clal} \rightarrow \mathrm{Xhol})$ & $\begin{array}{l}\text { pilD frameshift mutation-insertion } \\
\text { of Xhol linker at the Clal site }{ }^{\theta}\end{array}$ & $\begin{array}{l}\text { This work } \\
\text { This work }\end{array}$ \\
\hline GD $\triangle 180$ & $\begin{array}{l}\text { Deletion of nucleotides } 552-731^{c} \\
\text { In-frame pilD deletion }\end{array}$ & This work \\
\hline $\mathrm{GD} \triangle 230$ & $\begin{array}{l}\text { Deletion of nucleotides } 552-781^{\mathrm{c}} \\
\text { Out-of-frame pilD deletion }^{\mathrm{e}}\end{array}$ & This work \\
\hline GDX $\triangle$ Clal & $\begin{array}{l}\text { Deletion of } 0.5 \mathrm{~kb} \text { Clal iragment } \\
\text { spanning pilD-orf } X^{\theta}\end{array}$ & This work \\
\hline
\end{tabular}

a. VD300 is an MS11 derivative (Koomey et al., 1987).

b. All remaining listed strains are derived from $\mathrm{N} 400$.

c. Nucleotide sequence from Lauer et al. (1993).

d. Nucleotide sequence appears in the EMBL/GenBank/DDBJ Nucleotide Sequence Libraries under the accession number U19767. e. Contains downstream m-Tn3erm insertion in ORFY at position 836.

$8 \mu \mathrm{g} \mathrm{ml}^{-1}$ erythromycin. The pilE gene was amplified, by polymerase chain reaction (PCR), from selected mutants using appropriate primers and subjected to thermal cycle sequencing as directed by the manufacturer (Circumvent, New England Biolabs).

\section{DNA sequence analysis}

DNA sequencing of clones was performed using Sequenase 2.0 (United States Biochemical) as directed by the manufacturer. The complete sequence of both strands was determined by subcloning, as well as by the use of appropriate deletion constructs and unique oligonucleotide primers. This sequence appears in the EMBL/GenBank/DDBJ Nucleotide Sequence Data Libraries under the accession number U19767. The sequence spanning nucleotides 1 to 245 was derived from Lauer et al. (1993) and contains corrected sequences for pilD corresponding to those described by Dupuy and Pugsley (1994).

DNA and peptide sequence data were compiled and analysed by computer using both the MACVECTOR 3.5 (International Biotechnologies Inc.) and the University of Wisconsin Genetics Computer Group (UWGCG) sofiware packages (Devereux et al., 1984). Protein homologies were found using the TFASTA command and alignments were done using the PILEUP and PRETTY Commands. 


\section{Electron microscopy}

Sample grids were prepared by touching carbon-coated Formvar $3.05 \mathrm{~mm}$ grids (Tousimas Research Corp.) to individual bacterial colonies after approximately $18 \mathrm{~h}$ of growth at $37^{\circ} \mathrm{C}$ on solid media. Grids were air dried for $10 \mathrm{~min}$, then floated on a drop of $0.25 \%$ ammmonium molybdate for $30 \mathrm{~s}$ and again air dried. Transmission electron microscopy was performed using a Philips $\mathrm{CM}-10$ Transmission Electron Microscope.

\section{Measurements of transformation frequencies}

Transformation assays were carried out as previously described (Zhang et al., 1992) using genomic DNA isolated from nalidixic acid- or rifampicin-resistant gonococcal strains. Transformants were selected on media containing $10 \mu \mathrm{g} \mathrm{ml}^{-1}$ nalidixic acid or $5 \mu \mathrm{g} \mathrm{ml}^{-1}$ rifampicin.

\section{Construction of non-polar pilD mutations}

Plasmid $\mathrm{pF}-\mathrm{Y}_{2}$, a derivative of plasmid $\mathrm{pF}$ which contains a transposon insertion at position 861 (see Fig. 1), was used to construct deletions within pilD coding sequences. Following partial digestion of $\mathrm{pF}-\mathrm{Y}_{2}$, with Clal and Klenow treatment to produce blunt ends, a Xhol linker was inserted into the pilD Clal site. The resulting plasmid was designated pFpilD$X$ hol. Deletions within pilD were generated after digesting to completion with Xhol using exonuclease III as described (Ausubel et al., 1991). The pilD deletion plasmids were sequenced using primer 5'-GAAACTGTCAGTGCGGGG-3' to confirm the deletion locations and are designated as follows (nucleotide numbers are from the pilD sequence as reported by Lauer et al., 1993): pFpilD $\Delta 180$ (deletion of nucleotides 552-731), and pFpilD 230 (deletion of nucleotides 552-781).

Plasmid $\mathrm{pF} \Delta \mathrm{Cla}$ was constructed by digesting $\mathrm{pF}-\mathrm{Y} 2$ with Clal followed by re-ligation; this plasmid contains deletions of both pilD and orfX coding sequences (see Fig. 3).

Gonococcal GD(Clal $\rightarrow$ Xhol), GD $\Delta 180$, and GD $\Delta 230$ mutants were constructed by transformation of $\mathrm{N} 400$ with plasmids pFpilD - Xhol, pFpilD $\triangle 180$, and pFpilD $\Delta 230$, respectively, followed by selection on solid media containing $8 \mu \mathrm{gml}^{-1}$ erythromycin. Introduction of chromosomal deletion mutations was confirmed by Southern analysis of genomic DNA.

\section{Detection of pre-pilin processing}

Assays for pre-pilin processing activity were performed as follows: bacterial cell suspensions were made from overnight plates in $200 \mu \mathrm{l}$ sterile water and $200 \mu \mathrm{l} 2 \mathrm{x}$ sample PAGE buffer containing $0.1 \mathrm{M}$ Tris- $\mathrm{HCl}$ (pH6.8), $0.6 \mu \mathrm{M}$ B-mercaptoethanol, $400 \mathrm{mM}$ EDTA, 4\% SDS, and 20\% glycerol (v/v) and heated at $95 \mathrm{C}$ for $5 \mathrm{~min}$. Samples were fractionated by SDSPAGE on $15 \%$ gels and the proteins transferred to nitrocellulose. Filters were incubated with a 1:2000 dilution of polyclonal antibody GC2-66 generated against purified gonococcal pili or a 1:500 dilution of polyclonal antibody PAK 2-567 generated against $P$. aeruginosa PAK purified pili, then exposed to alkaline-phosphatase coupled goat anti-rabbit immunoglobulin antibodies (Tago Inc.). Pilin antigen was detected by the use of a colorimetric alkaline phosphate substrate. Details of the immunoblotting and antigen procedures have been published previously (Koomey et al., 1991).

\section{Acknowledgements}

We thank R. Fox and P. Lauer for technical assistance. This work was supported by Public Health Service grants Al27837 (M.K.), Al31494 and Al33493 (H.S.S.), and NIH Grant MO1 RR 00042. M.K. is a PEW Scholar in the Biomedical Sciences.

\section{References}

Albano, M., Breitling, R., and Dubnau, D.A. (1989) Nucleotide sequence and genetic organization of the Bacillus subtilis comG operon. J Bacteriol 171: 5386-5404.

Ashby, M.K., and Berquist, P.L. (1990) Cloning and sequence of IS1000, a putative insertion sequence from Thermus thermophilus HB8. Plasmid 24: 1-11.

Ausubel, F.M., Brent, R., Kingston, R.E., Moore, D.D., Seidman, J.G., Smith, J.G., and Struhl, K. (1991) Current Protocols in Molecular Biology. New York: Greene Publishing Associates \& Wiley Interscience.

Bally, M., Ball, G., Badere, A., and Lazdunski, A. (1991) Protein secretion in Pseudomonas aeruginosa: the $x c p A$ gene encodes an integral inner membrane protein homologous to Klebsiella pneumoniae secretion function protein Pulo. J Bacteriol 173: 479-486.

Biswas, G.D., Sox, T., Blackman, E., and Sparling, P.F. (1977) Factors affecting genetic transformation of Neisseria gonorrhoeae. J Bacteriol 129: 325-345.

Biswas, G.D., Thompson, S.A., and Sparling, P.F. (1989) Gene transfer in Neisseria gonorrhoeae. I Bacteriol 2: S24-S28.

Catlin, B.W. (1973) Nutritional profiles of Neisseria gonormoeae, Neisseria meningitidis, and Neisseria lactamica in chemically defined media and the use of growth requirements for gonococcal typing. J Inf Dis 128: 178-194.

Chung, Y.S., and Dubnau, D. (1995) ComC is required for the processing and translocation of ComGC, a pilin-like competence protein of Bacillus subtilis. Mol Microbiol 15: $543-551$.

Devereux, J., Haeberli, P., and Smithies, O. (1984) A comprehensive set of sequence analysis programs for the VAX. Nucl Acids Res 12: 387-395.

Dubnau, D. (1991) Genetic competence in Bacillus subtilis. Microbiol Rev 55: 395-424.

Dums, F., Dow, J., and Daniels, M. (1991) Structural characterization of protein secretion genes of the bacterial phytopathogen Xanthomonas campestris pathovar campestris: relatedness to secretion systems of other Gramnegative bacteria. Mol Gen Genet 229: 357-364.

Dupuy, B., and Pugsley, A. (1994) Type IV prepilin peptidase gene of Neisseria gonorrhoeae MS11: presence of a related gene in other piliated and nonpiliated Neisseria strains. J Bacteriol 176: 1323-1331.

Elleman, T.C., and Hoyne, P.A. (1984) Nucleotide sequence of the gene encoding pilin of Bacteroides nodosus, the causal organism of ovine footrot. J Bacteriol 160: 1184-1187.

(c) 1995 Blackwell Science Ltd, Molecular Microbiology, 16, 575-586 
Gilbert, W., Marchionni, M., and McKnight, G. (1986) On the antiquity of introns. Cell 46: 151-154.

Giron, J.A., Ho, A.S.Y., and Schoolnik, G.K. (1991) An inducible bundle-forming pilus of enteropathogenic Escherichia coli. Science 254: 710-713.

Gold, L. (1988) Posttranscriptional regulatory mechanisms in Escherichia coli. Annu Rev Biochem 57: 199-233.

deGroot, A., Heijnen, I., deCock, H., Filloux, A., and Tommassen, J. (1994) Characterization of Type IV pilus genes in plant growth-promoting Pseudomonas putida WCS358. J Bacteriol 176: 642-650.

Haas, R., Schwarz, H., and Meyer, T.F. (1987) Release of soluble pilin antigen coupled with gene conversion in Neisseria gonorrhoea. Proc Natl Acad Sci USA 84: 90799083.

Heckels, J.E. (1989) Structure and function of pili of pathogenic Neisseria species. Clin Microbiol Rev 2: S66-S73.

Hobbs, M., and Mattick, J. (1993) Common components in the assembly of type 4 fimbriae, DNA transfer systems, filamentous phage and protein-secretion apparatus: a general system for the formation of surface-associated protein complexes. Mol Microbiol 10: 233-243.

Jonsson, A.-B., Nyberg, G., and Normark, S. (1991) Phase variation of gonococcal pili by frameshift mutation in pilC, a novel gene for pilus assembly. EMBO $J$ 10: 477-488.

Kaufman, M.R., Seyer, J.M., and Taylor, R.K. (1991) Processing of TCP pilin by TcpJ typifies a common step intrinsic to a newly recognized pathway of extracellular protein secretion by Gram-negative bacteria. Genes Dev 5: 1834-1846.

Kellog, D.S., Cohen, I.R., Norins, L.C., Schroeter, A.L., and Reising, G. (1968) Neisseria gonorrhoeae II. Colonial variation and pathogenicity during 35 months in vitro. $J$ Bacteriol 96: 596-605.

Koga, T., Ishimoto, K., and Lory, S. (1993) Genetic and functional characterization of the gene cluster specifying expression of Pseudomonas aeruginosa pili. Infect Immun 61: $1371-1377$.

Koomey, M., Bergstrom, S., Blake, M., and Swanson, J. (1991) Pilin expression and processing in pilus mutants of Neisseria gonorrhoeae: critical role of Gly -1 in assembly. Mol Microbiol 5: 279-287.

Koomey, M., Gotschlich, E.C., Robbins, K., Bergstrom, S., and Swanson, J. (1987) Effects of recA mutations on pilus antigenic variation and phase transitions in Neisseria gonorrhoeae. Genetics 117: 391-398.

Lauer, P., Albertson, N.H., and Koomey, M. (1993) Conservation of genes encoding components of a type IV pilus assembly/ two-step protein export pathway in Neisseria gonorrhoeae. Mol Microbiol 8: 357-368.

Marrs, C.F., Schoolnik, G., Koomey, J.M., Hardy, J., Rothbard, J., and Falkow, S. (1985) Cloning and sequencing of a Moraxella bovis pilin gene. J Bacteriol 163: 132-139.

Mathis, L.S., and Scocca, J.J. (1984) On the role of pili in transformation of Neisseria gonorrhoeae. I Gen Microbiol 130: $3165-3173$.

McGee, Z.A., Johnson, A.P., and Taylor-Robinson, D. (1981) Pathogenic mechanisms of Neisseria gonorrhoeae: observations on damage to human fallopian tubes in organ culture by gonococci of colony type I or type 4. J Inf Dis 143: $413-422$.
Mohan, S., Aghion, J., Guillen, N., and Dubnau, D. (1989) Molecular cloning and characterization of $\operatorname{comC}$, a late competence gene of Bacillus subtilis. I Bacteriol 171: 6043-6051.

Nunn, D., Bergman, S., and Lory, S. (1990) Products of three accessory genes, pilB, pilC and pilD, are required for biogenesis of Pseudomonas aeruginosa pili. $J$ Bacteriol 172: 2911-2919.

Possot, O., and Pugsiey, A.P. (1994) Molecular characterization of PulE, a protein required for pullulanase secretion. Mol Microbiol 12: 287-299.

Potts, W.J., and Saunders, J.R. (1988) Nucleotide sequence of the structural gene for class I pilin from Neisseria meningitidis: homologies with the pilE locus of Neisseria gonorrhoeae. Mol Microbiol 2: 647-653.

Pugsley, A.P. (1993) The complete general secretory pathway in Gram-negative bacteria. Microbiol Rev 57: 50-108.

Pugsley, A.P., d'Enfert, C., Reyss, I., and Kornacker, M.G. (1990) Genetics of extracellular protein secretion by Gramnegative bacteria. Annu Rev Genet 24: 67-90.

Pugsley, A.P., and Reyss, I. (1990) Five genes at the $3^{\prime}$ end of the Klebsiella pneumoniae pulC operon are required for pullulanase secretion. Mol Microbiol 4: 365-79.

Rudel, T., van Putten, J.P.M., Gibbs, C.P., Hass, R., and Meyer, T.F. (1992) Interaction of two variable proteins (PilE and $\mathrm{PilC}$ ) required for pilus-mediated adherence of Neisseria gonorrhoeae to human epithelial cells. Mol Microbiol 6: 3439-3450.

Sandkvist, M., Morales, V., and Bagdasarian, M. (1993) A soluble protein required for secretion of cholera toxin through the outer membrane of Vibrio cholerae. Gene 123: $81-86$.

Seifert, H.S., Ajioka, R.S., Paruchuri, D., Heffron, F., and So, M. (1990) Shuttle mutagenesis of Neisseria gonorrhoeae: pilin null mutations lower DNA transformation competence. $J$ Bacteriol 172: 40-46.

Seifert, H.S., and Wilson, D. (1992) Characterization of a cryptic gene pair from Neisseria gonorrhoeae that is common to pathogenic Neisseria species. Infect Immun 60: $1232-1236$.

Shaw, C.E., and Taylor, R.K. (1990) Vibrio cholerae 0395 tcpA pilin gene sequence and comparison of the predicted protein structural features to those of type IV pilins. Infect Immun 58: 3042-3049.

Sparling, P.F. (1966) Genetic transformation of Neisseria gonorrhoeae to streptomycin resistance. J Bacteriol 92: 1364-1371.

Sparling, P.F., Biswas, G.D., and Sox, T.E. (1977) Transformation of the gonococcus. In The Gonococcus. Roberts R.B. (ed.). New York: John Wiley and Sons, pp. 155-176.

Strom, M.S., and Lory, S. (1986) Cloning and expression of the pilin gene of Pseudomonas aeruginosa PAK in Escherichia coli. J Bacteriol 165: 367-372.

Strom, M.S., and Lory, S. (1993) Structure-function and biogenesis of the Type IV pili. Annu Rev Microbiol 47: $565-$ 596.

Strom, M.S., Nunn, D.N., and Lory, S. (1993) A single bifunctional enzyme, PilD, catalyzes cleavage and $\mathrm{N}$ methylation of proteins belonging to the type IV pilin family. Proc Natl Acad Sci USA 90: 2404-2408.

Swanson, J. (1973) Studies on gonococcus infection IV. Pili, 
their role in attachment of gonococci to tissue culture cells. $J$ Exp Med 137: 571-589.

Swanson, J., Bergstrom, S., Robbins, K., Barrera, O., Corwin, D., and Koomey, J.M. (1986) Gene conversion involving the pilin structural gene correlates with pilus $^{+} /$pilus $^{-}$ changes in Neisseria gonorrhoeae. Cell 47: 267-276.

Swanson, J., Robbins, K., Barrera, O., Corwin, D., Boslego, J., Ciak, J., Blake, M., and Koomey, J.M. (1987) Gonococcal pilin variants in experimental gonorrhea. J Exp Med 165: 1344-1357.

Tønjum, T., Marrs, C., Rozsa, F., and Bøvre, K. (1991) The type IV pilin of Moraxella nonliquefaciens exhibits unique similarities with pilins of Neisseria gonorrhoeae and Bacteroides nodosus, J Gen Microbiol 137: 2483-2490.

Tonjum, T., Freitag, N.E., Namork, E., and Koomey, M. (1995) Identification and characterization of pilG, a highly conserved pilus-assembly gene in pathogenic Neisseria. Mol Microbiol 16: 451-464.
Turner, L.H., Lara, J.C., Nunn, D.N., and Lory, S. (1993) Mutations in the consensus ATP-binding site of XcpR and PilB eliminate extracellular protein secretion and pilus biogenesis in Pseudomonas aeruginosa. J Bacteriol 175: 4962-4969.

Walker, J.E., Saraste, M., Runswick, M.J., and Gay, N.J. (1982) Distantly related sequences in the $a$ and $b$ subunits of ATP synthase, myosin, kinases and other ATP-requiring enzymes and a common nucleotide binding fold. EMBO 1: 945-951.

Wilson, R. et al. (1994) $2.2 \mathrm{Mb}$ of contiguous nucleotide sequence from chromosome III of $C$. elegans. Nature 368 : $32-38$.

Zhang, Q.Y., DeRyckere, D., Lauer, P., and Koomey, M. (1992) Gene conversion in Neisseria gonorrhoeae: evidence for its role in pilus antigenic variation. Proc Natl Acad Sci USA 89: 5366-5370. 
Copyright of Molecular Microbiology is the property of Blackwell Publishing Limited and its content may not be copied or emailed to multiple sites or posted to a listserv without the copyright holder's express written permission. However, users may print, download, or email articles for individual use. 